\title{
Potential of Chanos chanos (Milkfish) Skin Gel Extract as an Alternative Approach in Treating First Degree Burn
}

\author{
Brian Kenneth E. Eduarte ${ }^{1}$, Nicole Andrey Acosta ${ }^{1}$, Jenela Pauline Lumanlan ${ }^{1}$, Jhevia E. \\ Magnampo $^{1}$, Diana Rose Medrano ${ }^{1}$, Kaori Ann B. Vicente ${ }^{1}$ and James Patrick C. Picar $^{1}$ \\ ${ }^{1}$ College of Medical Laboratory Science, Our Lady of Fatima University, Hilltop Subdivision, Lagro Novaliches \\ Quezon City, Philippines
}

\begin{abstract}
Background/Objectives: The fire related injuries such as burns are one of the main problems of the community. It is because of the insufficient ideas in wound healing and lack of financial capabilities resulting into selfmedication. Methods/Statistical analysis: In this study, the researchers will prepare an ointment from milkfish skin and scale added to soft paraffin in $70 \mathrm{C}$ until it congeals. The milkfish is known having high content of riboflavin and vitamin B complex that is a big impact to fasten the first-degree burn healing process. The milkfish skin and scales are also to be extracted using Gamma Irradiation as a manner of sterilization and for preservation of collagen and vitamin B content. The experimental rats will be induced of burn wounds by 5 seconds in the back part using cylindrical heat steel to be associated in $100 \mathrm{C}$ boiling water which will be treated with the prepared ointment. The epithelialization times, wound contraction and histological examination will be observed and the data recorded is to be analyzed using one-way ANOVA and repeated measures. Findings: This study deals with scientific experimentation to identify the potential of Milkfish skin and scale in wound healing. Improvements/Applications: If proven effective, it may be utilized as an alternative wound healing agent.
\end{abstract}

\section{Index Terms}

Riboflavin, Vitamin C complex, Gamma Irradiation, Milkfish, Burns

\footnotetext{
Corresponding author: J.P. Picar

jcpicar@fatima.edu.ph

- Manuscript received February 8, 2019.

- Revised February 27, 2019 ; Accepted March 25, 2019.

- Date of publication March 31, 2019.

(c) The Academic Society of Convergence Science Inc.

2619-8363 @ 2019 IJBSA. Personal use is permitted, but republication/redistribution requires IJBSA permission.
} 


\section{INTRODUCTION}

There are three major types of the burn phenomenon. It is widely discussed that a burn is a damage of body's tissue that is normally caused by radiation, sunlight, electricity, chemicals and more often heat. Swelling, scarring, blisters are most common causes of burns. In a more serious case this may be the reason of shock or even death. Another kind is an inhalation injury, caused by breathing smoke. There are three types of burns and these are first-degree burns damage only the outer layer of skin, second-degree burns damage the outer layer and the layer underneath and lastly third-degree burns damage or destroy the deepest layer of skin and tissues underneath. They also can lead to infections because they damage your skin's protective barrier. The factors to be investigated are the depth of the injury and how much of physiological body covers the burn allocating the treatment. More often, creams and widely used antibiotics are capable of preventing and treating possible infections. Treatment may be in need of the cleaning process, skin replacement and an assurance of patients sustained nutrition and fluids in cases of more serious burns. (Bethesda MD, 2017)

The researchers arrived into a topic treating burned wound because of the recent cases regarding about burned wounds. In some documented investigation fires causing chaos are the costliest preventable emergency in the Philippines but still in need of different basis and statistic researches. In the year 2012, the agency of the Philippines named the Department of Health specifically its umbrella Health Emergency Alert Reporting System (HEARS) shows classical figures that fire related incidents gather $39 \%$ of most of the affair reported to the Health Emergency Alert Reporting System in between 2005 to 2009 . This data showcases 749 injuries and 263 death casualties. The said causative chaos is noted to be the biggest problem in between year 2010 until 2012 and still striking coequal geographic regions. Figuratively, a estimated 883 fire and 824 related issues are reported. The Metro Manila also reported as the most prior region where the economic chaos due happened (Velasco, 2013)

The researchers proposed this topic "The Potential of Chanos chanos (Milkfish) Extract as an Alternative Approach in Treating First-degree Burns" to give efficient way on how the society and the public can find a much capable way in treating first-degree burn. The researchers must find an eschar formation, as a sign of tissue repair, faster than the normal physiological skin repair. In the recent epoch, the leading way on how to treat firstdegree burn induces an expensive financial worth, in this way, using the extract gel of Milkfish, the researchers aim to give a more satisfying and faster way of treating first-degree burn rather than the issued time in treating the said burn.

The possibility of Milkfish in treating firstdegree burn promises a wide positive range of result. The Bangus or commonly called Milkfish is a pacific salt water fish characterized by silver-colour lay eggs in shallow coastal water that is capable living in lowsalinity water. This aquatic resource is an origin of animal protein, Vitamin B-complex and further selenium. Yet, it is also a revelatory source of calories, saturated fats, fats and even percentage of cholesterol. In per serving of Milkfish funds $116 \%$ of Vitamin B12, 24\% of Vitamin B6, 15\% of pantothenic Acid and $44 \%$ of Niacin that the Food and Nutrition Board of the Institute of Medicine confides adults to consume diurnal.

The serving of Milkfish bids $25 \%$ of the phosphorus and the selenium that human physiology must consume every day. Phosphorus has an important role in red blood cell oxygenation and selenium is important in the thyroid and immune function. Milkfish resulted having a delineate amounts of iron, calcium, zinc and potassium. All of the said four vitamins are known to be water soluble B-complex vitamins. They play vital roles in the physiological metabolism especially in central nervous system function, skin health function and DNA release, hormone and red blood cell formation. Milkfish also bear trace amounts of riboflavin, vitamin A and folate. Milkfish is noted having no amount of vitamin C, D, E or K significantly. (Gray, 2017)

Relatively studies conclude that Milkfish skin and scale contained moisture $64.74 \%$, ash that is $2.43 \%$, lipid is $4.76 \%$, protein results $23.74 \%$, and carbohydrate were $4.34 \%$ respectively. Milkfish skin also noted to enter prerigor at no days, postrigor in between 14 days, rigormortis in just 8 days and finally decomposed within just 23 days of chilled storage. Milkfish began to experience damages in rigormortis by such occurrence of degeneration[4].

\section{MATERIALS AND METHODS}

\section{A. Research design}

The study embodies and employs scientific experimental research design involving to different categories. This is an experiment where the researchers manipulated one variable, and control/randomizes the rest of the variables. It has a control group, the subjects are randomly assigned between the groups, and the researcher only tested one effect at a time.

The proposals created set-ups where in the researchers observed whether there will be significant changes among the set-ups. Scientifically, the researchers also noticed that there are different 
pointers and improvements throughout experimentation. The study utilized the qualitative and quantitative design through experimental figures and process. Quantitatively, the researchers are to analyze if what are the time of wound contraction and epithelialization times. Quantitative data is to sum up in data that are in numerical form statistically. Qualitatively, the researchers are to analyze and investigate the general results on how the product will affect the model organisms by means of the different set-up and control outcome based on observations and documentations. In the study, milkfish extracts are to be distributed in different setups by different amounts, and to be distributed as well into different amounts of chemicals in the process of creating an ointment, and this is quantified by means of statistical analysis using different sets of analysis.

\section{B. Collection of Materials}

The Milkfish skin and scale are collected in a public market at Dagupan City. Albino mice are obtained from a Bureau of Animal Industries (BAI) accredited provider. The test animal is acclimatized and taken care in a BAI accredited animal house in Quezon City, Philippines.

\section{Extraction of Milkfish}

The extract of Milkfish skin and scales are delivered and processed at the Philippine Nuclear and Research Institute using Gamma Irradiation as a physical method for extraction and preservation of collagen and anti-oxidants. It also includes the influence of gamma irradiation on microbial inactivation, color changes, sensory properties, and shelf-life of treated skin and scale extract.

\section{Preparation of Experimental Ointment}

In set up A, $1 \mathrm{ml}$ of base is added to $1.5 \mathrm{ml}$ of Milkfish extract. In set up B, $1.5 \mathrm{ml}$ of base is added to $1 \mathrm{ml}$ of Milkfish extract. In set up C, $2 \mathrm{ml}$ of base is added to $0.5 \mathrm{ml}$ of Milkfish extract. In set up D, $2.25 \mathrm{ml}$ of base is added to $0.25 \mathrm{ml}$ of Milkfish extract.

\section{E. Experimental Animals}

Albino rats (Sprague dawley) are housed in a BAI accredited animal house. The animals were grouped into 5 , consisting 5 mice each group. Burn wounds were inflicted on rats in Groups A to D, which were then applied with the ointment immediately. The last groups were burn-wounded, and did not receive any treatment and served as the negative control.

\section{F. Creation of Burn Wood}

Full thickness first degree burned wounds were inflicted using methods of Cai and colleagues and Yaman and colleagues modified accordingly. Test animal hair was shaved at the back area and disinfected with 70\% isopropyl alcohol. Mice and rabbit, for sensitivity testing, were anaesthetized using xylazin ezoletil topical anesthesia. A cylindrical heat steel of $1 \mathrm{~cm}$ diameter was heated at $100 \mathrm{C}$ boiling water. This was then made in contact with the skin of the mice for 10 seconds.

\section{G. Administration of Treatment}

Each mouse were given their first topical treatment after evaluation of the burn wound to be of the right depth and size. Mice are to the group in the following:

Group A will receive $1.5 \mathrm{ml}$ Milkfish extract twice a day

Group B will receive $1 \mathrm{ml}$ Milkfish extract twice a day

Group C will receive $0.5 \mathrm{ml}$ Milkfish extract twice a day

Group D will receive $0.25 \mathrm{ml}$ Milkfish extract twice a day

Negative Control will receive distilled water twice a day.

Each group has 5 replicates. Treatment is to administer twice a day for fourteen days.

\section{H. Evaluation of Wound}

Wound contraction is a gross assessment of how much of the injury is healed. A significant area of the burn wound among the test animal was observed by researchers in the different set-ups. The completely healed wound were observed on the day 14 on all mice that were given the Milkfish extract ointment.

Gross examination of the wound were determined daily to check on the color, presence of exudates, swelling and consistency of tissues surrounding the wound. Wound size was computed based on the following formula:

$\%$ wound closure $=\underline{\text { initial wound-final area of wound } \mathrm{x} 100}$ Initial are of the wound

\section{Histological Examination}

Burned skin tissue samples were collected after the experimentation on the mice for histological examination following methods by Yaman and colleagues. Tissues were fixed in $10 \%$ neutralbuffered formalin solution and brought in Central Luzon State University, Department of Pathology 
and Laboratory section for preparation of slides. The prepared slides stained with hematoxylin and eosin that were observed under the light microscope by a qualified veterinary pathologist.

\section{J. Epitheliazation times}

The average epithelialization time was noted also by researchers. This was a note of the fastness of epithelial cells replenishment. All extracts from Milkfish skin and scales were statistically analysed using SSD by the university statistician.

\section{K. Statistical Analysis}

Numerical data were analyzed using Analysis of variance (ANOVA) at 5\% level of significance and Duncan Multiple Range Test (DMRT) as post-hoc test. Statistical analysis is carried out using SPSS version 22.

\section{RESULTS}

Table 1. Percentage WOUnd CONTRACtion OF BURN WOUND MODELS IN RAT

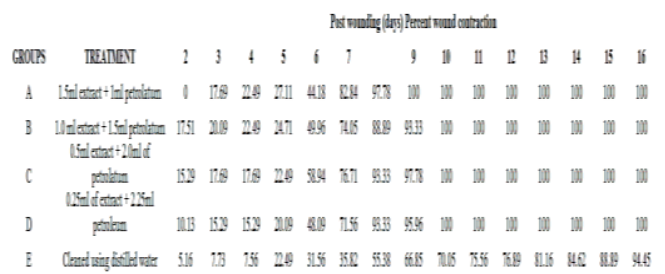

This table shows the percent wound contraction from no wound (day 2) contraction seen up to the $16^{\text {th }}$ day having $100 \%$ wound closure for group A-D over incomplete percent wound closure for Group E (Negative control).

Fig. 1. Histopathology Examination

The photomicrograph of skin of burn mice with H\&E stain showing epidermis layer of the skin $(\mathrm{x} 400)$, test after $16^{\text {th }}$ day of treatment.

\section{Group A}

(a) Granulation tissue formation. The burn reveals degeneration of hair follicle. There is absence of acute cellular swelling and bacteria, presence of complete fibrosis and absence of edema. Set-up A (Day 9).
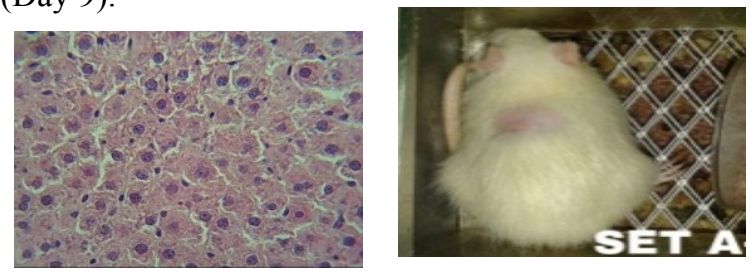

Group B

(b) Presence of Hair follicle with fibrous. There is mild inflam severity, presence of fibrosis, scab, bacteria and edema absence. Set-up B (Day 12).
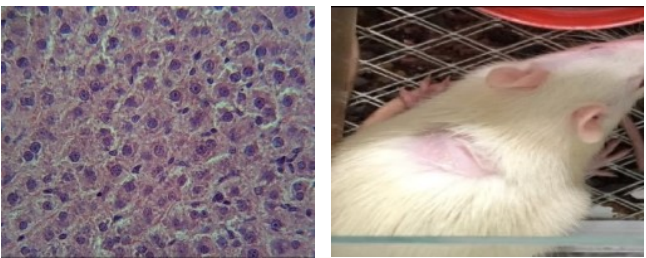

\section{Group C}

(c) Shows sebaceous gland degeneration and burn reveals collagen. There is absence of scabs, edema and bacteria and hemorrhage. There is mild inflam severity and presence of fibrosis. Set-up C (Day 12).
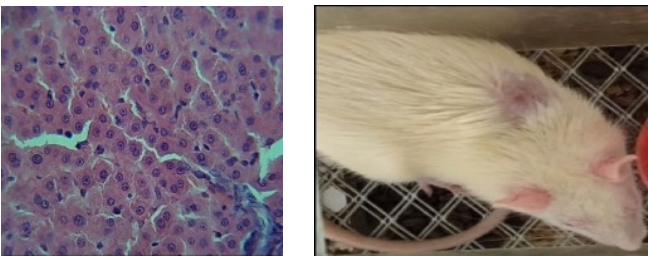

\section{Group D}

(d) Shows granulation and tissue formation and partial surface ulceration. There is also absence of scab, hemorrhage, edema and bacteria. There is mild inflame severity and presence of complete fibrosis. Set-up D (Day 13)
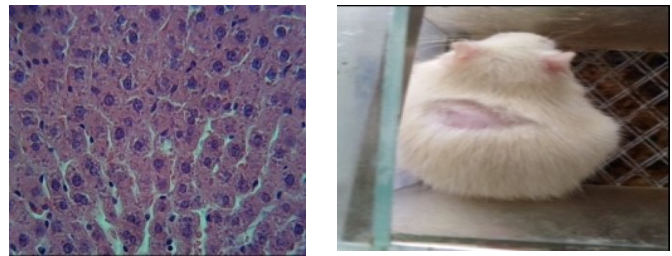

Group E

(e) Shows dermal disorganization. There is also presence of edema and inflammation. There is in mild inflame severity and hemorrhage but minimal fibrosis is present. Set-up E (Day >19)

Do not put captions in "text boxes" linked to the figures. Do not put borders around the outside of your figures. Use the abbreviation "Fig." even at the beginning of a sentence. Do not abbreviate "Table." Tables are numbered with Arabic numerals.
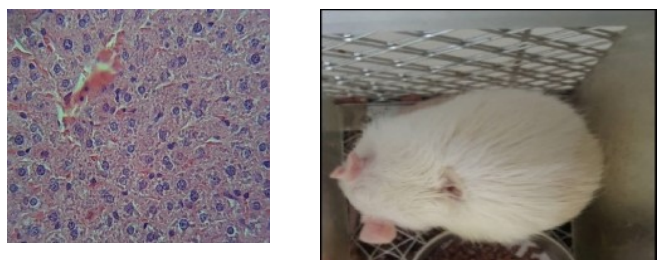
Table 2. ANOVA OF $16^{\mathrm{TH}}$ DAY OF WOUND CONTRACTION

\begin{tabular}{|c|c|c|c|c|c|c|c|}
\hline \multicolumn{3}{|c|}{ Dependent Variable } & \multirow{2}{*}{$\begin{array}{c}\text { Mean } \\
\text { Differenc } \\
\text { e (I-J) }\end{array}$} & \multirow[t]{2}{*}{$\begin{array}{c}\text { Std. } \\
\text { Error }\end{array}$} & \multirow[t]{2}{*}{ Sig. } & \multicolumn{2}{|c|}{$\begin{array}{l}55 \% \text { Confidence } \\
\text { Interval }\end{array}$} \\
\hline & & & & & & $\begin{array}{l}\text { Lower } \\
\text { Bound }\end{array}$ & $\begin{array}{l}\text { Upper } \\
\text { Bound }\end{array}$ \\
\hline \multirow[t]{20}{*}{ Day16 } & A & 2.00 & 0.00000 & 0.00000 & .549 & 0.0000 & 0.0000 \\
\hline & & 3.00 & 0.00000 & 0.00000 & & 0.0000 & 0.0000 \\
\hline & & 4.00 & 0.00000 & 0.00000 & & 0.0000 & 0.0000 \\
\hline & & 5.00 & 4.44440 & 2.72163 & & -7.6549 & 16.5437 \\
\hline & B & 1.00 & 0.00000 & 0.00000 & .549 & 0.0000 & 0.0000 \\
\hline & & 3.00 & 0.00000 & 0.00000 & & 0.0000 & 0.0000 \\
\hline & & 4.00 & 0.00000 & 0.00000 & & 0.0000 & 0.0000 \\
\hline & & 5.00 & 4.44440 & 2.72163 & & -7.6549 & 16.5437 \\
\hline & C & 1.00 & 0.00000 & 0.00000 & & 0.0000 & 0.0000 \\
\hline & & 2.00 & 0.00000 & 0.00000 & & 0.0000 & 0.0000 \\
\hline & & 4.00 & 0.00000 & 0.00000 & & 0.0000 & 0.0000 \\
\hline & & 5.00 & 4.44440 & 2.72163 & .549 & -7.6549 & 16.5437 \\
\hline & D & 1.00 & 0.00000 & 0.00000 & & 0.0000 & 0.0000 \\
\hline & & 2.00 & 0.00000 & 0.00000 & & 0.0000 & 0.0000 \\
\hline & & 3.00 & 0.00000 & 0.00000 & & 0.0000 & 0.0000 \\
\hline & & 5.00 & 4.44440 & 2.72163 & .549 & -7.6549 & 16.5437 \\
\hline & E & 1.00 & -4.44440 & 2.72163 & .549 & -16.5437 & 7.6549 \\
\hline & & 2.00 & -4.44440 & 2.72163 & .549 & -16.5437 & 7.6549 \\
\hline & & 3.00 & -4.44440 & 2.72163 & .549 & -16.5437 & 7.6549 \\
\hline & & 4.00 & -4.44440 & 2.72163 & .549 & -16.5437 & 7.6549 \\
\hline
\end{tabular}

The mean difference is significant at the 0.05 level. The data shows the significant difference of set-up A-D that utilize milkfish extract as burn wound healing agent over the negative control in $16^{\text {th }}$ day of healing.

Table 3. POST-HOC TEST OF 16TH DAY OF PERCENT WOUND

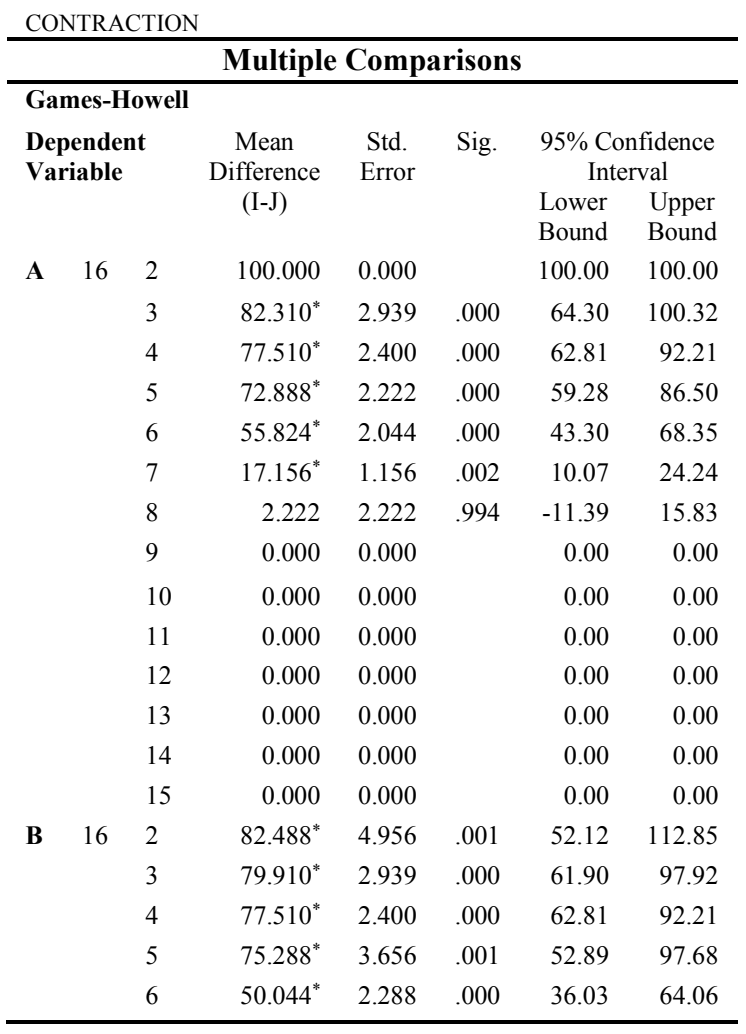

\begin{tabular}{|c|c|c|c|c|c|c|c|}
\hline & & 7 & $25.952^{*}$ & 2.488 & .007 & 10.71 & 41.19 \\
\hline & & 8 & $11.110^{*}$ & .000 & .000 & 11.11 & 11.11 \\
\hline & & 9 & 6.666 & 2.721 & .573 & -10.01 & 23.34 \\
\hline & & 10 & 0.000 & 0.000 & & 0.00 & 0.00 \\
\hline & & 11 & 0.000 & 0.000 & & 0.00 & 0.00 \\
\hline & & 12 & 0.000 & 0.000 & & 0.00 & 0.00 \\
\hline & & 13 & 0.000 & 0.000 & & 0.00 & 0.00 \\
\hline & & 14 & 0.000 & 0.000 & & 0.00 & 0.00 \\
\hline & & 15 & 0.000 & 0.000 & & 0.00 & 0.00 \\
\hline \multirow[t]{14}{*}{ C } & 16 & 2 & $84.710^{*}$ & 2.400 & .000 & 70.01 & 99.41 \\
\hline & & 3 & $82.310^{*}$ & 2.939 & .000 & 64.30 & 100.32 \\
\hline & & 4 & $82.310^{*}$ & 2.939 & .000 & 64.30 & 100.32 \\
\hline & & 5 & $77.510^{*}$ & 2.400 & .000 & 62.81 & 92.21 \\
\hline & & 6 & $41.064^{*}$ & 2.067 & .001 & 28.40 & 53.73 \\
\hline & & 7 & $23.288^{*}$ & 2.353 & .009 & 8.87 & 37.70 \\
\hline & & 8 & 6.666 & 2.721 & .573 & -10.01 & 23.34 \\
\hline & & 9 & 2.222 & 2.222 & .994 & -11.39 & 15.83 \\
\hline & & 10 & 0.000 & 0.000 & & 0.00 & 0.00 \\
\hline & & 11 & 0.000 & 0.000 & & 0.00 & 0.00 \\
\hline & & 12 & 0.000 & 0.000 & & 0.00 & 0.00 \\
\hline & & 13 & 0.000 & 0.000 & & 0.00 & 0.00 \\
\hline & & 14 & 0.000 & 0.000 & & 0.00 & 0.00 \\
\hline & & 15 & 0.000 & 0.000 & & 0.00 & 0.00 \\
\hline \multirow[t]{14}{*}{ D } & 16 & 2 & $89.866^{*}$ & 4.681 & .001 & 61.19 & 118.55 \\
\hline & & 3 & $84.710^{*}$ & 2.400 & .000 & 70.01 & 99.41 \\
\hline & & 4 & $84.710^{*}$ & 2.400 & .000 & 70.01 & 99.41 \\
\hline & & 5 & $79.910^{*}$ & 2.939 & .000 & 61.90 & 97.92 \\
\hline & & 6 & $51.912^{*}$ & 1.868 & .000 & 40.47 & 63.36 \\
\hline & & 7 & 28.440 & 0.000 & & 28.44 & 28.44 \\
\hline & & 8 & 6.666 & 2.721 & .573 & -10.01 & 23.34 \\
\hline & & 9 & 4.444 & 2.721 & .884 & -12.23 & 21.12 \\
\hline & & 10 & 0.000 & 0.000 & & 0.00 & 0.00 \\
\hline & & 11 & 0.000 & 0.000 & & 0.00 & 0.00 \\
\hline & & 12 & 0.000 & 0.000 & & 0.00 & 0.00 \\
\hline & & 13 & 0.000 & 0.000 & & 0.00 & 0.00 \\
\hline & & 14 & 0.000 & 0.000 & & 0.00 & 0.00 \\
\hline & & 15 & 0.000 & 0.000 & & 0.00 & 0.00 \\
\hline \multirow[t]{14}{*}{$\mathbf{E}$} & 16 & 2 & $89.289^{*}$ & 4.018 & .000 & 70.89 & 107.69 \\
\hline & & 3 & $86.711^{*}$ & 4.018 & .000 & 68.31 & 105.11 \\
\hline & & 4 & $86.889^{*}$ & 5.584 & .000 & 58.55 & 115.22 \\
\hline & & 5 & $71.955^{*}$ & 3.454 & .000 & 56.60 & 87.31 \\
\hline & & 6 & $62.889^{*}$ & 3.685 & .000 & 46.36 & 79.42 \\
\hline & & 7 & $58.623^{*}$ & 4.190 & .000 & 39.20 & 78.05 \\
\hline & & 8 & $39.065^{*}$ & 3.753 & .000 & 22.17 & 55.96 \\
\hline & & 9 & $27.597^{*}$ & 4.035 & .005 & 9.10 & 46.10 \\
\hline & & 10 & $24.397^{*}$ & 2.908 & .001 & 11.07 & 37.72 \\
\hline & & 11 & $18.889^{*}$ & 2.972 & .006 & 5.41 & 32.37 \\
\hline & & 12 & $17.557^{*}$ & 2.819 & .010 & 4.39 & 30.73 \\
\hline & & 13 & 13.289 & 4.198 & .264 & -6.18 & 32.76 \\
\hline & & 14 & 9.823 & 3.606 & .409 & -6.29 & 25.94 \\
\hline & & 15 & 5.555 & 2.484 & .652 & -8.00 & 19.11 \\
\hline
\end{tabular}




\section{DISCUSSION}

Wound healing is a complex process, which interruption could lead to a delayed healing or excessive fibrosis. Delay in wound healing increases the possibility of getting infected, inappropriate recovery. Several effects of Chanos chanos (Milkfish) Extract possess high collagen compounds and riboflavin contents with anti-oxidant and antiinflammatory effects, could also prevent collagen production and accumulation. In addition, the beneficial effect of Collagen and Riboflavin on wound healing quality and hence leaving more skin has been shown, which probably confirm its effect on increased level of vascular endothelial growth factor and accelerated vessel formation. Consistently, the superiority of Set-up A over the groups in view of vessel formation is indicative of this effect. Monitoring burned wounds during the study demonstrated the significant effect of Milkfish extract in contrast to negative control on the wounds' recovery acceleration. A day-by-day treatment interaction effect was noted for wound contraction.

The burned wound healing effect of the extract of Chanos chanos (Milkfish) against firstdegree burn was observed by experimentation using Sprague dawley rats and measured the wound contraction using repeated measures by means of area of the wound and fastness of the days of treated. This is measured using ANOVA 1, ANOVA 2 and Repeated measures. The lower and upper bound for $95 \%$ confidence interval for mean are illustrated in table 4.1.

Table 1 shows the significant differences between set-ups. There are 5 albino rats per group, values represents Mean \pm Standard Deviation, ${ }^{*} p<0.05$ (Comparison of Set-up A to Set-up E), the results were analyzed statistically using one-way analysis of variance and results that set-up A gives the fastest area wound contraction. There are significant main effect of day on the rate of wound closure overall, shows that there are marked differences in terms of wound closure in Set-up A to Set-up E.

Table 2 shows the differences between the last days of healing per set-up.

Table 3 shows the comparison, in percent wound contraction, of group A to group B, group B to group $\mathrm{C}$, group $\mathrm{C}$ to group $\mathrm{D}$, group $\mathrm{D}$ to group $\mathrm{E}$. The researchers identified that there are significant differences of set-ups A-D over set-up E.

In Appendix A, Plate 6 shows that the Setup A possesses the fastest ability of wound closure in terms of days and area of closure. Followed by Setup C next, Set-p D followed by Set- up B and noted to be the least effective in wound contraction among set-ups is Set-up E.

Therefore, using an ointment from milkfish extract has the fastest burn wound healing capability than just cleaning it using water. On the other hand, the group having higher amount of milkfish extract over amount of petroleum jelly possesses rapid wound contraction. Yet, the slowest wound contraction among groups using milkfish extract has faster wound contraction than negative control.

\section{Conclusion}

There is a significant difference between the negative control and the concentrations mentioned. Therefore, the researchers conclude that the ointment from the extract of milkfish is effective in healing a burned wound and more effective than negative control.

The negative control shows significant differences between the set-ups that utilize milkfish extract. The negative control still shows edema, an interpretation that the first degree burn is not yet fully healed and no presence of complete wound contraction at the 19th day while the other group A performed complete wound contraction at the 9th day.

The researchers are able to utilize Milkfish as a primary variable in the healing process and found out that there will be no any skin related reactions after performing the 24 hours sensitivity testing. There is also a factor affecting the capability of milkfish extract in wound healing process. This is the amount of concentration used in the experiment. The higher the concentration of milkfish extract the faster it will heal. The milkfish extract is proven to be sterile and has wound healing effect and possesses collagen compounds and Riboflavin that helps in healing process.

Using milkfish extract in wound healing process has a potential in more rapid healing than just cleaning it using water or not just healing it at all. Among set-ups the set-up having higher amount of milkfish extract than amount of petroleum jelly has more rapid healing than small amount of milkfish extract.

\section{ACKNOWLEDGMENT}

The preferred spelling of the word "acknowledgment" in American English is without an "e" after the "g." Use the singular heading even if you have many acknowledgments. Avoid expressions such as "One of us (S.B.A.) would like to thank ... ." Instead, write "S.B.A. thanks ... ." This work was supported in part by the U.S. Department of Commerce under Grant BS123456 (sponsor and financial support acknowledgment goes here). 


\section{REFERENCES}

[1] Albert A. Espiritu (2016), Burn wound healing potential of Bixa orellana Linn leaf extracts on albino mice, JMPS, 4(1): 84-87

[2] Connect Tissue Res, 41 (2000), pp. 195-211

[3] Esra Kupeli Akkol (2008), Evaluation of the Wound Healing Potential of Achillea bibersteinii Afan by in vivo excision and incision models, Article ID 474026

[4] Nur-A-Sayed (2012), Effect of Gamma Radiation at 20 degree Celsius on Microbiological Changes in Wild and Cultured Stinging Catfish, Heteropneustes fossilis, ISSN 2078-4589

[5] Guidolin D., Vacca A., Nussdorfer G.G., Ribatti D. A new image analysis method based on topological and fractal parameters to evaluate the angiostatic activity of docetaxel by using the Matrigel assay in vitro. Microvasc Res. 2004, 67, 117-124.

[6] J.F. Wang, M.E. Olson, C.R. Reno, W. Kulyk, J.B. Wright, D.A. HartMolecular and cell biology of skin wound healing in a pig model

[7] J.F. Wang, M.E. Olson, D.K. Ball, D.R. Brigsotock, D.A. HartRecombinant connective tissue growth factor modulates porcine skin fibroblast gene expression

[8] Joel W. Beam, EdD, LAT, ATC (2008), Occlussive Dressing and the Healing of Standardized Abrasions, University of Florida, 43(6),600-607

[9] John V. Bennett, M.D. \& Philip S. Brachman, M.D (2014) Hospital Infections 10th Edition, Brown and Company Inc. ISBN 0-316-08992-3

[10] Md. Kawser Amed, Masudul Hasan, 2009, Effect of Gamma Radiation in Combination with Low temperature refrigeration on the chemical, microbiological and organoleptic changes in Pampus chinensis, ISSN 1817-3098

[11] Richard \& Staley (2004) Burn Care and Rehabilitation: Principles and Practice by F.A. Davis Company/ Reginald L. Richard, Marlys J. Staley. ISBN 0-8036-7361-2

[12] S. Kameshwaran, R. Senthilkumar, S. Themozhi. (2014). Wound healing Potential of Ethanolic Extract of Tecoma stans flowers in Rats, Pharmacologia, 5(6), 215-221.

[13] Sayyed Yazdan Asadi, Pouya Parsaei, Mehrdad Karimi (2012), Effect of green tea (Camellia sinensis) extract on healing process of surgical wounds in rat, (2013) 332-337

[14] Sima Taheri, Thohirah Lee Abdullah (2014), Antioxidant Capacities and Total Phenolic Contents Enhancement with Acute Gamma Irradiation in Curcuma alismatifolia Leaves, ISSN 1422-0067

[15] Sreenivasan Sasidharan (2010), Wound Healing Potential of Elaeis guineensis Jacq Leaves in an Infected Albino Rat Model, ISNN 1420-3049

[16] Verhaegen P.D., Res E.M., van Engelen A., Middelkoop E., van Zuijlen P.P. (2010). A reliable, non-invasive measurement tool for anisotropy in normal skin and scar tissue. Skin Res Technol. $16,325-331$

[17] Wound Repair Regen, 11 (2003), pp. 220-229 